\title{
Empiric Vancomycin Dosing Recommendations in Pediatrics
}

\author{
Sonia Patel* and Laura Hagan \\ Assistant Professor of Pharmacy, Philadelphia College of Osteopathic Medicine, USA
}

*Corresponding author: Sonia Patel, Assistant Professor of Pharmacy, Philadelphia

College of Osteopathic Medicine, USA.

\author{
Received Date: October 03, 2018 \\ Published Date: January 04, 2019
}

\section{Abstract}

Objectives: The primary objective was to determine the percentage of patients within specific age groups that fell within goal vancomycin trough range with every 6 hour and every 8-hour interval dosing. Secondary objectives were mean trough in each age group and patients that fell within goal versus not within goal.

Methods: A retrospective chart review of 157 pediatric patients for one year (August 2009-2010) was conducted. Four groups were assessed: patients one month to less than eight years of age receiving vancomycin at eight- and six-hour intervals (groups one and two respectively) and eight to eighteen years of age receiving vancomycin at eight and six hour intervals (groups three and four respectively).Inferential statistics were used to conduct independent t-tests and Fischer's exact tests to compare mean steady state trough levels, percentages and $\mathrm{mg} / \mathrm{kg}$ dosing.

Results: Percentage of goal vancomycin trough values were as follows: $21 \%$ group one, 59\% group two, $42 \%$ group three and $40 \%$ group four. For steady state trough levels, $\mathrm{p}=0.001$ for groups one vs. two and the rest were not statistically significant (groups three vs. four, one vs. three and two vs. four).

Conclusion: Patients one month to less than eight years of age may be more likely to achieve a goal vancomycin trough of ten to fifteen with every six-hour interval; however, a conclusion cannot be made on a dosing interval for patients eight to eighteen years of age since p-values were not statistically significant.

\section{Introduction}

Vancomycin is a time-dependent glycopeptide antibiotic prescribed for infections caused by suspected and confirmed gram-positive organisms, frequently skin and soft tissue infections caused by methicillin-resistant Staphylococcus aureus (MRSA). Vancomycin is commonly used in the hospital setting and use of vancomycin is increasing as resistance to gram positive organisms continues to increase [1-5].

Vancomycin has age-dependent pharmacokinetics, and in pediatric patients, total body clearance of vancomycin is two to three times higher than that of adults. Clearance of vancomycin in infants and children less than eight years old may exceed that of older children. Because clearance of vancomycin is higher in younger children, it may be more difficult to reach goal trough levels in patients under the age of eight with eight hour interval dosing. Most American texts and a study done by Schaad et al. recommend empiric pediatric dosing of vancomycin with 40 to $60 \mathrm{mg} / \mathrm{kg} /$ day divided every six to eight hours [4]. No recommendations are made specific to age groups within the pediatric population $[1,3,4]$. Vancomycin peak and trough serum concentrations are routinely obtained in an effort to maximize efficacy and minimize potential toxicity from vancomycin therapy. However, in clinical practice, trough levels alone are more commonly used [2,6]. The purpose of this review is to establish optimal empiric dosing recommendations for vancomycin in pediatric patients based on age.

\section{Materials and Methods}

This was a retrospective study done at The Medical Center in Columbus, Georgia. The Medical Center has a twenty-eightbed pediatric floor and a seven bed pediatric intensive care unit. The study consisted of a chart review of pediatric patients from August 2009-August 2010 who received vancomycin with trough monitoring. Inclusion criteria consisted of patients one month to 18 years of age who had vancomycin trough monitoring performed. Exclusion criteria consisted of patients less than one month and greater than 18 years of age and patients in the pediatric intensive 
care unit. Renal function was not accounted for because pediatric patients at this institution have relatively normal renal function.

This study was IRB approved by The Medical Center. Patients were stratified into four groups according to age and dosing interval: one month to less than eight years with every six-hour interval, one month to less than eight years with every eight-hour interval, eight years to eighteen years with every six-hour interval and eight years to eighteen years with every eight-hour interval. Patients who did not have a steady state trough value recorded were excluded (thirty minutes prior to the fifth dose is usually considered steady state at our institution for every six hour or every eight-hour interval) (Figure 1). Patient age, gender, vancomycin dose in $\mathrm{mg} /$ $\mathrm{kg}$, dosing interval and indication were obtained and recorded in an Excel spreadsheet (Figure 2). The defined target range at this institution for a goal trough was $10-15 \mathrm{mg} / \mathrm{L}$. The primary objective was to determine whether every eight-hour interval versus every six-hour interval would be more likely to achieve a goal trough in pediatric patients based on age. The primary endpoint was percent of patients that fell within goal trough range in each group and the secondary endpoint was the mean steady state trough level in each group.

\section{Results}

Statistical Package for Social Sciences (SPSS) was used for statistical analysis. Independent t-tests were conducted to compare the means of dosing $(\mathrm{mg} / \mathrm{kg})$ and steady state trough levels for each of the four groups. Fisher's exact test was used to determine the percent of patients within goal trough range for each of the four groups. Statistical analysis compared age as well as dosing interval.

One hundred and fifty-seven patients were evaluated for inclusion into the study. Of the 157 patients, twenty-seven patients were excluded because they did not have a steady state trough level recorded or had a trough drawn in error. One hundred and thirty patients were analyzed and had data recorded. The patients were divided into four groups: one month to less than eight years with an every six hour interval ( $n=75)$, one month to less than eight years with an every eight hour interval $(n=19)$, eight years to eighteen years with an every six hour interval $(n=5)$ and eight years to eighteen years with an every eight hour interval $(n=31)$.

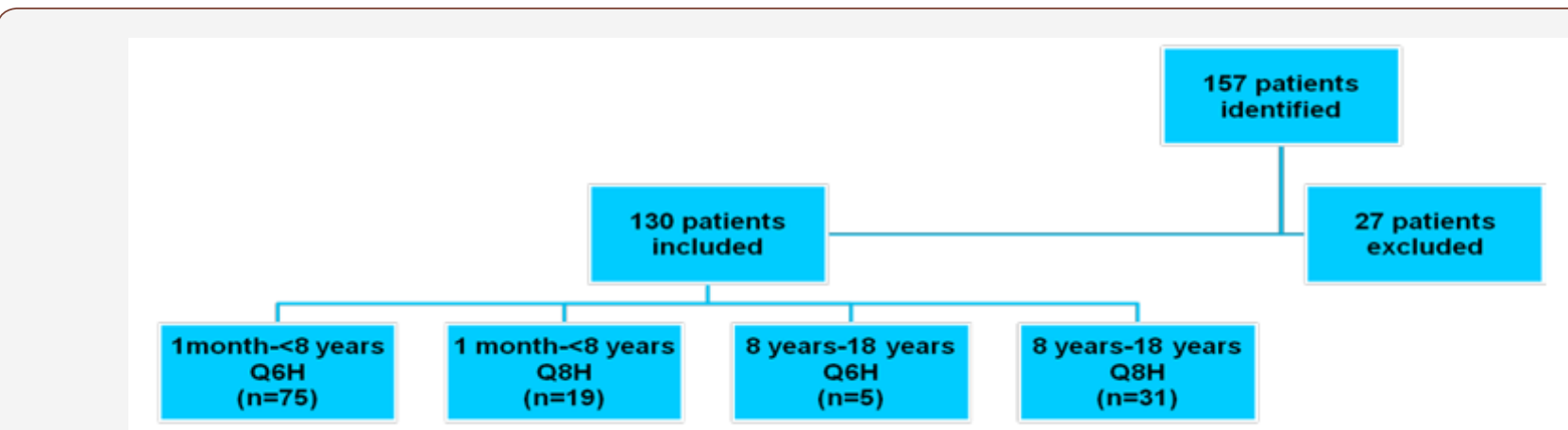

Figure 1: Patients identified.

\begin{tabular}{|c|c|}
\hline Indication & \# of patients (n=130) \\
\hline Abscess/Cellulitis & 78 \\
\hline Pneumonia & 26 \\
\hline Sepsis & 5 \\
\hline MRSA Otorrhea & 5 \\
\hline Colonic Ulcers & 4 \\
\hline Other & 12 \\
\hline
\end{tabular}

\begin{tabular}{|c|c|}
\hline Group & Average Age (yrs) \\
\hline 1 month-<8 years Q6H & 3.9 \\
\hline 1 month-Q8H & 4.3 \\
\hline 8 years-18 years Q6H & 11 \\
\hline 8 years-18 years Q8H & 13.6 \\
\hline
\end{tabular}

Figure 2: Demographics.

The most common indication was abscess/cellulitis ( $\mathrm{n}=78$ of 130). Twenty-six patients had non- MRSA confirmed pneumonia, five had sepsis, five had MRSA otorrhea, four had colonic ulcers and twelve had "other" as an indication. "Other" consisted of fever of unknown origin, leukocytosis, sickle cell crisis and empiric indications (Figure 1). The mean age in one month to less than eight years with every six-hour interval was 3.9 years and 4.3 years for one month to less than eight years with every eight-hour interval. For eight to eighteen years with every six-hour interval and eight years to eighteen years with every eight-hour interval, the mean age was 11 years and 13.6 years, respectively (Figure 2).

The mean dosing $(\mathrm{mg} / \mathrm{kg})$ values ranged from $9.9-20 \mathrm{mg} / \mathrm{kg}$ or $40.8-56.8 \mathrm{mg} / \mathrm{kg} /$ day. Mean dose $(\mathrm{mg} / \mathrm{kg}$ ) for one month to less than eight years with an every six hour interval, one month to less than eight years with an every eight hour interval, eight years to eighteen years with an every six hour interval and eight years to eighteen years with an every eight hour interval was $13.2 \mathrm{mg} / \mathrm{kg}$, $13.6 \mathrm{mg} / \mathrm{kg}, 14.2 \mathrm{mg} / \mathrm{kg}$ and $14.5 \mathrm{mg} / \mathrm{kg}$, respectively (Figure 3). Mean steady state trough values for one month to less than eight years with an every six hour interval, one month to less than eight years with an every eight hour interval, eight years to eighteen years with an every six hour interval and eight years to eighteen 
years with an every eight hour interval was $11.2 \mathrm{mcg} / \mathrm{ml}, 7.9 \mathrm{mcg} /$ $\mathrm{ml}, 16.2 \mathrm{mcg} / \mathrm{ml}$ and $10.4 \mathrm{mcg} / \mathrm{ml}$ with a defined goal trough range of $10-15 \mathrm{mcg} / \mathrm{ml}$ (Figure 4). When comparing mean steady state trough value for one month to less than eight years with every sixhour interval versus every eight-hour interval, $p=0.000$ and for eight years to eighteen years with every six-hour interval versus every eight-hour interval, $\mathrm{p}=0.005$.

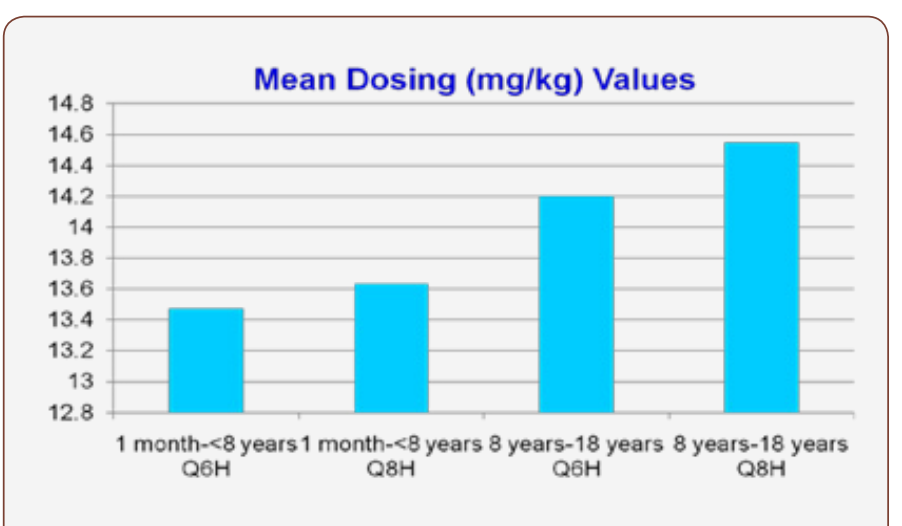

Figure 3: Mean Dosing (mg/kg) Values.
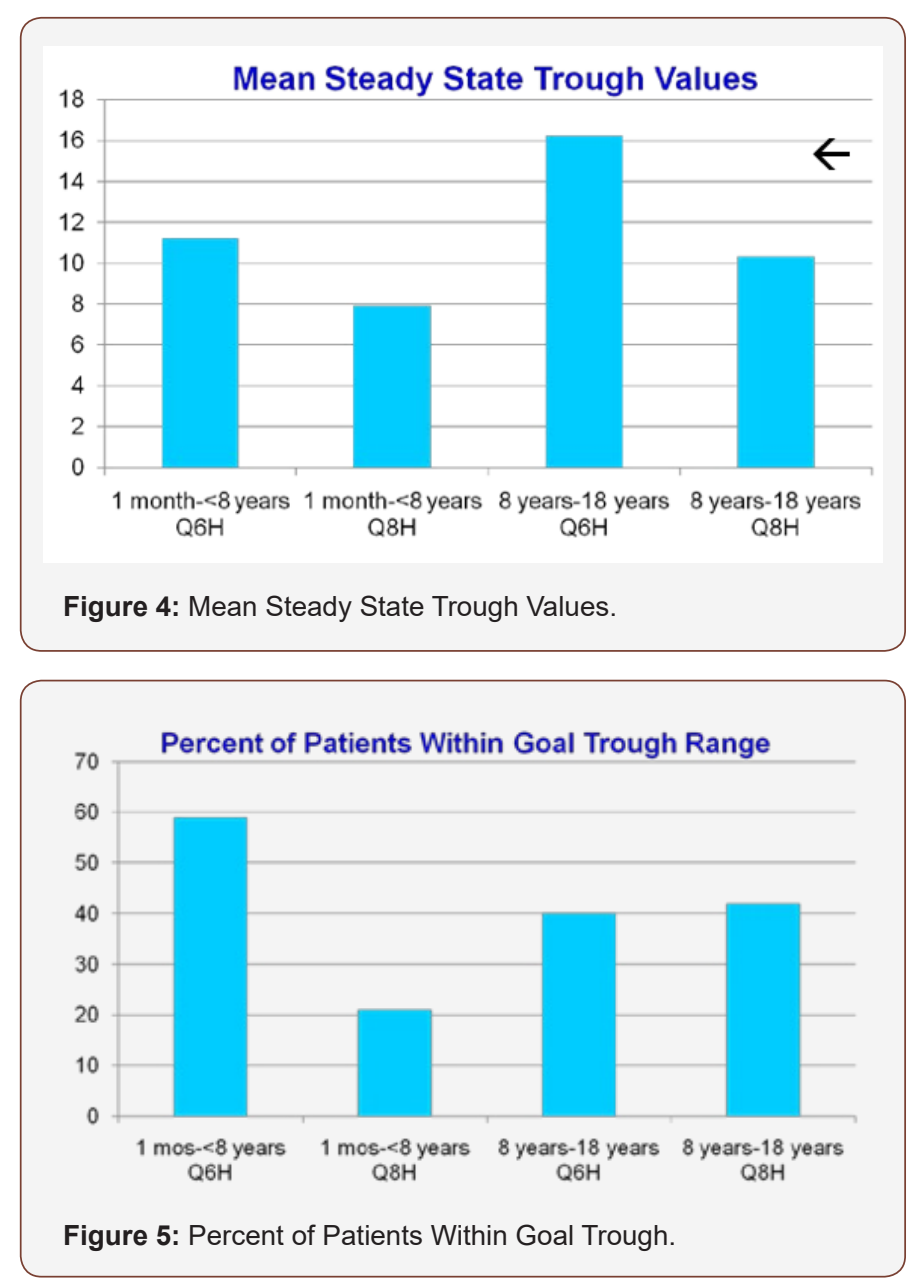

Forty-four of seventy-five patients (59\%) fell within goal trough range for one month to less than eight years with every sixhour interval and four of nineteen patients (21\%) fell within goal trough range for one month to less than eight years with every eight-hour interval. Two of five patients (40\%) fell within goal trough range for eight years to eighteen years with every six-hour interval and thirteen of thirty-one patients (42\%) fell within goal trough range for eight years to eighteen years with every eight-hour interval (Figure 5). When comparing percent within goal trough range for one month to less than eight years with every six-hour interval versus every eight-hour interval, $p=0.004$ and $p=1.000$ when comparing percent within goal trough range for eight years to eighteen years with every six-hour interval versus every eighthour interval.

Overall, patients fell within goal trough range more often for one to less than eight years with every six-hour interval and eight years to eighteen years with every eight-hour interval. However, the percent of patients within goal trough range for eight years to eighteen years with every six-hour interval (40\%) vs. every eighthour interval $(42 \%)$ not statistically significant.

\section{Discussion}

The purpose of this study was to determine an optimal empiric vancomycin dosing interval for pediatric patients based on age. From the data presented in this study, it can be concluded that children one month to less than eight years will be more likely achieve a goal trough level with every six-hour interval. For eight years to eighteen years, the mean steady state trough fell within goal range with every eight-hour interval and was supratherapeutic for every six-hour interval; it can be concluded that with every eight-hour interval with eight years to eighteen years, it would be more likely to achieve a goal trough with an every eight hour interval. However, the difference in the percentage that fell within goal trough range for eight years to eighteen years with an every six hour interval and an every eight hour interval was not statistically significant which is most likely due to the small sample size in one of the groups ( $n=5$ in the eight years to eighteen years with an every six hour interval and $n=31$ in the eight years to eighteen years with an every eight hour interval). One study by Spears and Koch studied 53 patients one month to eighteen years of age.

Seventeen of the patients received intravenous vancomycin and the dose ranged from $25 \mathrm{mg} / \mathrm{kg} /$ day to $180 \mathrm{mg} / \mathrm{kg} /$ day. Based upon the data from this study, the authors concluded that vancomycin 40 $\mathrm{mg} / \mathrm{kg} /$ day IV was adequate [7].

Another study conducted by Schaad et al. studied 55 patients. Dosing ranged from 10 to $15 \mathrm{mg} / \mathrm{kg}$ and they monitored serial vancomycin concentrations. They also concluded that vancomycin $40 \mathrm{mg} / \mathrm{kg} /$ day is adequate. However, they also were able to conclude that $60 \mathrm{mg} / \mathrm{kg} /$ day was needed for patients with staphylococcal central nervous system disease [8-10].

There were a few limitations to this study. A possible limitation could include that renal function was not accounted for because pediatric patients at this institution have relatively normal renal function. Another limitation was that if there were laboratory errors in drawing troughs or errors in hang time of vancomycin, it was not accounted for since it was not always documented by the pharmacist. In addition, an uneven distribution of groups was most likely the cause for the eight years to eighteen years group to have not statistically significant results for the percent of patients that fell within goal trough range. 
More studies on empiric vancomycin dosing in pediatric patients based on age need to be done that have a more even distribution of groups. Data from studies can be used for hospitalwide implementation in various hospitals and to help develop agedependent pediatric empiric vancomycin dosing guidelines.

\section{Acknowledgements}

The authors would like to acknowledge Lori Hornsby PharmD, BCPS for her hard work and help with statistical analysis and interpretation. This work was presented at the Georgia Society of Health Pharmacists spring meeting at Callaway Gardens, Georgia, the Southeastern Residency Conference in Athens, Georgia and as a grand round's presentation in Columbus, Georgia.

\section{Conflict of Interest}

No conflict of interest.

\section{References}

1. Benner KW, Worthingon MA, Kimberlin DW, Hill K, Buckley K, et al. (2009) Correlation of vancomycin dosing to serum concentrations in pediatric patients: a retrospective database review. J Pediatr Pharmcol Ther 14(2): 86-93.

2. Glover ML, Cole E, Wolfsdorf J (2000) Vancomycin dosage requirements among pediatric intensive care unit patients with normal renal function. J Crit Care 15(1): 1-4.
3. Rodvold KA, Everett JA, Pryka RD, Kraus DM (1997) Pharmacokinetics and administration regimens of vancomycin in neonates, infants and children. Clin Pharmacokinet 33(1) :32-51.

4. Schaad UB, Mc Cracken GH, Nelson JD (1980) Clinical pharmacology and efficacy of vancomycin in pediatric patients. Antibiot Annu 96(1): 119126.

5. Keyserling HL, Sincowitz-Cochran FL, Harris JM, Levine GL, Siegel JD, et al. (2003) Vancomycin use in hospitalized pediatric patients. Pediatrics 112(2): 104-111.

6. Tetelbaum M, Finkelstein Y, Nava-Ocampo AA, Koren G (2005) Understanding drugs in children: pharmacokinetic maturation. division of clinical pharmacology and toxicology, department of pediatrics and population health services, The hospital for sick children; Toronto, Canada 26(9): 321- 328.

7. Spears RL, Koch R (1959) The use of vancomycin in pediatrics. Antibiot Annul 1960: 798-803.

8. Miles MV, Li L, Lakkis H, Youngblood J, McGinnis P (1997) special considersations for monitoring vancomycin concentrations in pediatric patients. Ther Drug Monit 19(3):265-270.

9. Frymoyer A, Hersh AL, Benet LZ, Guglielmo BJ (2009) Current recommended dosing of vancomycin for children with invasive methicillin-resistant staphylococcus aureus infections is inadequate. Pediatr Infect Dis J 28(5): 398-402.

10. Schaible DH, Rocci ML, Alpert GA, Campos JM, Paul MH, et al. (1986) Vancomcyin pharmacokinetics in infants: relationships to indices of maturation. Pediatr Infect Dis J 5(3): 304-308. 